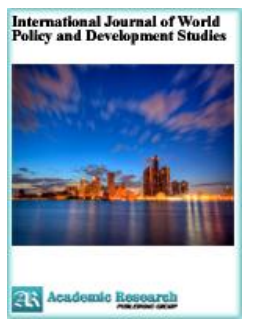

International Journal of World Policy and Development Studies ISSN(e): 2415-2331, ISSN(p): 2415-5241

Vol. 3, No. 1, pp: 1-9, 2017

URL: http://arpgweb.com/?ic=journal\&journal=11\&info=aims

\title{
Crime Surge and Institutional Weakness: are They Associated? Evidence from a Conflict Country
}

\author{
Ibrahim A. Onour
}

Professor of Financial Econometrics School of Management Studies University of Khartoum, Sudan

\begin{abstract}
This paper investigates the degree of association between major four crimes in Sudan, including illegal drug trafficking, murder, theft, and prostitution, with indicators of institutional weakness that include surge in other four crimes: duty \& customs, forgery, passport related, and firearms $\&$ ammunition crimes. These later four crimes has been considered indicators of institutional weakness because upswing in these crimes is a reflection of corruption or negligence, or incompetence of institutional performance in the country. The canonical correlation test result indicates there is a very high and significant association between the major four crimes and the indicators of institutional weakness. This finding implies institutional weakness can nurture crime surge in the country. Cluster analysis indicates the type of crimes in conflict states of Darfor region are featured in the rest of the country except in the capital state, Khartoum which represent a separate cluster on its own. Cluster analysis also indicate murder crime is connected with prostitution; and theft crime is associated with firearms \& ammunition crimes; custom \& duty crimes connected with passport -related and illegal drugs crimes. However, illegal drugs crime is connected with murder, theft, and prostitution crimes.
\end{abstract}

Keywords: Crimes; Multivariate analysis; Sudan.

\section{Introduction}

Crime rate is considered important indicator of society's well-being and a measure of quality of living or dwelling in specific area in a town or a region. Increase in crime rate in certain area has sever negative impact on welfare of inhabitants in that area and divert scarce resources from support to productive activities to crime combating requirements. Understanding the nature and dynamics of crime requires thorough knowledge of its interdependence across different locations in the country. To do so, we need first to identify the major crimes in all eighteen states in the country, and then cluster or classify crimes based on similarities and commonalities in different states in the country, and finally identify their relationship with major indicators of institutional weakness in the country.

To address these issues we employed multivariate statistical methods including, profile analysis, principal component \& factor analysis, and cluster analysis. The remaining parts of this research structured as follows: section two explores international evidences of crimes institutional links, section three includes some basic statistical analysis of crimes in Sudan, section four presents the methodology of the research, section five discusses the empirical findings, the final section concludes the study.

\section{Institutional Links}

There is increasing concern of association of crime trend with indicators of state weakness and institutional corruption. In this respect World bank indexing of state weakness relate weak states to countries that fail to secure their populations from violent conflict and crime surge. On a similar direction Rotberg (2002) indicates weak states fail to provide services that reduce domestic threats to the national order and social structure, as arms and drug trafficking become more rampant. Also indicated that failed states exhibit flawed institutions in which the judiciary lack independence and citizens lose trust and confidence on court system for redress or remedy, especially against the state. The Tenth United Nations Survey of Crime Trends and

Operations of Criminal Justice Systems, revealed that in Mexico high levels of corruption in the police, judiciary have contributed greatly to the crime increase, as drug trafficking, assault and theft make up the vast majority of crimes in that country. Given such evidences in this research our primary goal to investigate institutional links with the major four crimes, theft, murder, illegal drugs, and prostitution in Sudan. Since there is lack of reliable statistics on judiciary and police corruption in this country, we relied on statistical indicators that may reveal institutional weakness. These indicators include passport-related crimes, custom \& duty crimes, fire arms \& 
ammunition crimes, and forging crimes. We stand on strong belief that surge in these four crimes in any country is a reflection of weakness in law enforcement institutions particularly the judiciary and police departments.

\section{Data Analysis}

Crime data in this research has been collected from the annual report of crime statistics for the year 2016, published by the Interior Ministry of Sudan.

Crime statistics summary in table (1) indicates across all eighteen states of the country Khartoum state is taking the largest share of illegal drugs trafficking, while other states such as Senar, South Kordofan, and Gedarif also rank above the national average level in illegal drug crime rates. Regarding the theft crime, Kharoum and AlGazira records the highest rates in the country. Murder crime is exclusively higher in Khartoum, and conflict states of South Kordofan, West Kordofan and three Darfor states (North, South, West). However, Central Darfor state record the lowest crime rates in all 18 states in the country, and the other remaining eight states in the country are relatively safe as their crime levels recorded below the national average level ${ }^{1}$.

Table (2) indicates there is significant upswing of theft and drug trafficking in 2015, as theft crime increased by $11 \%$ on national level, and about $14 \%$ in Khartoum state alone, whereas drug trafficking increased by about $7 \%$ on national level, and by $27 \%$ in Khartoum state during the same year. Similar conclusion can be deduced from figure (1) too.

Table-1. Crime distribution map

\begin{tabular}{|c|c|c|c|c|}
\hline Name of state & Drugs & Theft & Murder & Adultery \\
\hline $\begin{array}{c}\text { National } \\
\text { average }\end{array}$ & 418 & 5520 & 101 & 184 \\
\hline Khartoum & $\sqrt{ }+$ & $\checkmark+$ & $\checkmark$ & $\checkmark t$ \\
\hline Northern & & & - & \\
\hline \multicolumn{5}{|l|}{ Nile River } \\
\hline White Nile & & & & $\checkmark$ \\
\hline \multicolumn{5}{|l|}{ Blue Nile } \\
\hline AlGazira & & $\checkmark$ & & $\checkmark$ \\
\hline Senar & $\checkmark$ & & & \\
\hline \multicolumn{5}{|l|}{ North Kordofan } \\
\hline West Kordofan & & & $\checkmark$ & \\
\hline South Kordofan & $\checkmark$ & & $\checkmark$ & $\checkmark$ \\
\hline North Darfor & & & $\checkmark$ & \\
\hline South Darfor & & & $\checkmark t$ & \\
\hline West Darfor & & & $\checkmark$ & \\
\hline Central Darfor & $\bullet$ & $\bullet$ & & $\bullet$ \\
\hline East Darfor & & & $\checkmark$ & \\
\hline \multicolumn{5}{|l|}{ Red Sea } \\
\hline Gadarif & $\checkmark$ & & & \\
\hline Kassala & & & & \\
\hline
\end{tabular}

Table-2. Crime statistics

\begin{tabular}{c|l|l|l|l}
\hline Type of crime & $\mathbf{2 0 1 3}$ & $\mathbf{2 0 1 4}$ & $\mathbf{2 0 1 5}$ & \% change (2014-2015) \\
\hline Murder - national level & 1429 & 2036 & 1817 & -10.6 \\
$-\quad$ Khartoum state & 273 & 247 & 249 & 0.8 \\
& & & & \\
\hline Theft - national level & 71768 & 89502 & 99361 & 11 \\
$-\quad$ Khartoum state & 32691 & 44747 & 50995 & 13.9 \\
\hline Adultery - national level & 3829 & 3207 & 3322 & 3.5 \\
$-\quad$ Khartoum state & 1467 & 1172 & 1164 & -0.6 \\
\hline Illegal drugs -national level & 7490 & 6946 & 7419 & 6.8 \\
$-\quad$ Khartoum state & 3006 & 2264 & 2879 & 27.1 \\
\hline
\end{tabular}

\footnotetext{
${ }^{1}$ Some government officials in Central Darfour state believe that the low crime rate statistics reported in this state is due to reluctance of citizens to report crimes since a majority of them are internally displaced refugees who lacks confidence and trust in the local police and security.
} 


\section{Methodology}

\subsection{Principal Component Analysis}

Principal component analysis deals with a single sample of $\mathrm{n}$ observation vectors $y_{1}, y_{2}, \ldots \ldots y_{p}$ that form a group of points in a multi-dimensional space. Principal component analysis can be applied to any distribution of y, but it can be easier to visualize geometrically if the group of points is ellipsoidal. If the variables $y_{1}, y_{2}, \ldots \ldots y_{p}$ are correlated the cluster of points is not oriented parallel to any of the axes represented by $y_{1}, y_{2}, \ldots \ldots y_{p}$.

Principal component analysis explores the natural axes of the swarm of points with origin at the mean vector of ys. This is done by translating the origin to the mean vector of ys and then rotating the axes. The axes can be rotated by multiplying each y by an orthogonal matrix $A$ :

$\mathrm{Z}_{\mathrm{i}}=\mathrm{Ay}_{\mathrm{i}}$ such that $\mathrm{A}$ is orthogonal $\mathrm{A}^{\prime} \mathrm{A}=\mathrm{I}$ and the distance to the origin is unchanged: $Z_{i}^{\prime} Z_{i}=\left(A y_{i}\right)^{\prime}\left(A y_{i}\right)=y_{i}^{\prime} A^{\prime} A y_{i}=y_{i}^{\prime} y_{i}$

Thus, an orthogonal matrix transforms yi to a point zi that is the same distance from the origin, and the axes are effectively rotated.

Finding the axes of the ellipsoid is equivalent to finding the orthogonal matrix A that rotates the axes to line up to the natural extensions of the swarm of points so that the new variables (principal components) $\mathrm{z} 1, \mathrm{z} 2, \ldots \ldots \mathrm{zp}$ in $\mathrm{Z}=\mathrm{Ay}$ are uncorrelated.

\subsection{Canonical Correlation}

Canonical correlation investigates linear association between two sets of variables:

$y^{\prime}=\left(y_{1}, y_{2}, \ldots ., y_{p}\right)$ and $x^{\prime}=\left(x_{1}, x_{2}, \ldots ., x_{q}\right)$. For simplification purposes we denote each of these two sets as $\mathrm{y}$ and $\mathrm{x}$. It is important to realize that canonical correlation is an extension of multiple correlation, which is the correlation between one y and several x's. The canonical correlation, however, is the correlation between multiple dependent variables (y matrix) and multiple independent variables (x matrix). Canonical correlation analysis is often a useful complement to a multivariate regression analysis.

In the case of several y's and several x's the covariance structure associated with two sub-vectors $\mathrm{y}$ and $\mathrm{x}$ can be partitioned as:

$S=\left(\begin{array}{ll}s_{y y} & s_{y x} \\ s_{x y} & S_{x x}\end{array}\right)$

Where $s_{y y}$ is the pxp sample covariance matrix of the y's, $s_{y x}$ is the pxq matrix of the sample covariances between the y's and the x's, and $s_{x x}$ is the qxq sample covariance matrix of the $x$ 's.

The best overall measure of association is the largest squared canonical correlation (maximum eigenvalue) $r_{1}^{2}$ of $s_{y y}^{-1} s_{y x} s_{x x}^{-1} s_{x y}$.

The canonical correlations can also be obtained from the partitioned correlation matrix of the y's and x's,

$R=\left(\begin{array}{ll}R_{y y} & R_{y x} \\ R_{x y} & R_{x x}\end{array}\right)$

Where $R_{y y}$ is the pxp sample correlation matrix of the $y$ 's, $R_{y x}$ is the pxq matrix of sample correlations between the $y$ 's and the $x$ 's, and $R_{x x}$ is the qxq sample correlation matrix of the $x$ 's.

\subsubsection{Tests of Significance}

Under $\mathrm{H}_{0}$ ( the null-hypothesis) there is no (linear) relationship between the y's and the $\mathrm{x}$ 's, and $\mathrm{H}_{0}$ is equivalent to the statement that all canonical correlations $r_{1} r_{2} \ldots \ldots r_{s}$ are non-significant. The significance of $r_{1} r_{2} \ldots . . r_{s}$ can be tested by Wilk's test:

$$
\Lambda_{1}=\frac{|S|}{\left|S_{y y}\right|\left|S_{x x}\right|}=\frac{|R|}{\left|R_{y y}\right|\left|R_{x x}\right|}
$$

Which is distributed as $\Lambda_{\mathrm{p}, \mathrm{q}, \mathrm{n}-1-\mathrm{q}}$. We reject $\mathrm{H}_{0}$ if $\Lambda_{1} \leq \Lambda_{\alpha}$. Critical values $\Lambda_{\alpha}$ are available in table A.9 in Rencher (2002).

$v_{H}=q$ and $V_{E}=n-1-q>$. Also $\Lambda_{1}$ is expressible in terms of the squared canonical correlations:

$$
\Lambda_{1}=\prod_{i=1}^{s}\left(1-r_{i}^{2}\right)
$$

If the parameters exceed the range of critical values for Wilks' critical values, we can use the Chi-square approximation as:

$$
X^{2}=-\left[n-\frac{1}{2}(p+q+3)\right] \ln \Lambda_{1}
$$

Which approximately distributed as Chi-square with pq degrees of freedom. We reject $\mathrm{H}_{0}$ if $X^{2} \geq X_{\alpha}^{2}$

\subsection{Cluster Analysis}

Cluster analysis deals with identification of the observation vectors that are similar and group them into clusters. As a result, to capture similarities between groups cluster analysis use the distance between each pair of observations in the data. Since a distance increases as two units become further apart, distance is used as a measure of dissimilarity between groups. A common distance function is the Euclidean distance between two vectors: 
$x=\left(x_{1}, x_{2}, \ldots . x_{p}\right)^{\prime}$ and $y=\left(y_{1}, y_{2}, \ldots \ldots y_{p}\right)^{\prime}$

defined as:

$$
d(x, y)=\sqrt{(x-y)^{\prime}(x-y)}=\sqrt{\sum_{j=1}^{p}\left(x_{j}-y_{j}\right)^{2}}
$$

To adjust for change in variances and covariances among variables we can use the standardized distance measure:

Where $\mathrm{S}$ is the sample covariance matrix.

$$
d(x, y)=\sqrt{(x-y)^{\prime} S^{-1}(x-y)}
$$

The most common cluster technique, is hierarchical method that include single linkage (nearest neighbor) and other clustering algorithms (see Rencher (2002), for details). Hierarchical clustering algorithm involve a sequential process, that merge a cluster into another cluster in each step sequentially. As a result, in the hierarchical algorithm the number of clusters decreases until we end up with one single cluster.

\subsection{Profile Analysis}

Profile analysis is useful when y is $N_{p}(\mu, \Sigma)$ and the variables in y are measured in the same units with approximately equal variances, and the objective is to compare the means $\mu_{1}, \mu_{2} \ldots \mu_{p}$. The pattern connecting several means is called a profile, and some times the primary purpose can be to compare between several sample means.

In the single sample case to compare the means $\mu_{1}, \mu_{2} \ldots \mu_{p}$, the basic hypothesis is that the profile is level or flat:

$H_{0}: \mu_{1}=\mu_{2}=\cdots .=\mu_{p}$ vs. $H_{1}: \mu_{j} \neq \mu_{k}$ for some $j \neq k$

For a multivariate approach that allow for correlation between variables, we first express the null-hypothesis as p-1 comparisons,

$$
H_{0}=\left(\begin{array}{c}
\mu_{1}-\mu_{2} \\
\mu_{2}-\mu_{3} \\
\cdot \\
\mu_{p-1}-\mu_{p}
\end{array}\right)=\left(\begin{array}{l}
0 \\
\cdot \\
0
\end{array}\right)
$$

Which can be expressed as $H_{0}: C \quad \mu=0$ where

$$
C=\left(\begin{array}{cccc}
1 & -1 & 0 . . & 0 \\
0 & 1 & -1 . . & 0 \\
. & . & . & \\
0 & 0 & 0 . . & -1
\end{array}\right)
$$

When $H_{0}: C \mu=0$ is true, $C \bar{y}$ is $N_{p-1}\left(0, c \Sigma c^{\prime} / n\right)$ and

$$
T^{2}=(C \bar{y})^{\prime}\left(\frac{C S C^{\prime}}{n}\right)^{-1}(C \bar{y})=(C \bar{y})^{\prime}\left(C S C^{\prime}\right)^{-1}(C \bar{y})
$$

Is distributed as $T_{p-1, n-1}^{2}$. We reject $H_{0}: C \mu=0$ if $T^{2} \geq T_{\propto, p-1, n-1}^{2}$. The dimension $\mathrm{p}-1$ correspond to the number of rows of $\mathrm{C}$.

In the case of two-sample profile analysis instead of the hypothesis that $\mu_{1}=\mu_{2}$, we test the hypothesis $H_{01}: \mu_{1, j}-$ $\mu_{1, j-1}=\mu_{2, j}-\mu_{2, j-1}$ for $\mathrm{j}=2,3, \ldots . . \mathrm{p}$, or

$$
H_{01}=\left(\begin{array}{c}
\mu_{12}-\mu_{11} \\
\mu_{13}-\mu_{12} \\
\cdot \\
\mu_{1 p}-\mu_{1, p-1}
\end{array}\right)=\left(\begin{array}{c}
\mu_{22}-\mu_{21} \\
\mu_{23}-\mu_{22} \\
\cdot \\
\mu_{2 p}-\mu_{2, p-1}
\end{array}\right)
$$

Which can be written as $H_{01}: C \mu_{1}=C \mu_{2}$ using the contrast matrix

$$
C=\left(\begin{array}{cccc}
-1 & 1 & 0 . . & 0 \\
0 & -1 & 1 . . & 0 \\
. & \cdot & . & \\
0 & 0 & 0 . . & 1
\end{array}\right)
$$

From the two sample, $y_{11}, y_{12}, \ldots . y_{1 n 1}$ and $y_{21}, y_{22}, \ldots . y_{2 n 2}$ we obtain $\bar{y}_{1,} \bar{y}_{2}$ and $S_{p l}$ as estimates of $\mu_{1}, \mu_{2}$, and $\Sigma$. Then the null-hypothesis test:

$H_{01}: C \mu_{1}-C \mu_{2}=0$, the random vector $C \bar{y}_{1}-C \bar{y}_{2}$ is $N_{p-1}\left(0, \frac{c \Sigma c^{\prime}}{n_{1}+n_{2}}\right)$ and $T^{2}=\frac{n_{1} n_{2}}{n_{1}+n_{2}}\left(\bar{y}_{1}-\bar{y}_{2}\right)^{\prime} C^{\prime}\left(C S_{p l} C^{\prime}\right)^{-1} C\left(\bar{y}_{1}-\bar{y}_{2}\right)$ is distributed as $T_{p-1, n_{1}+n_{2}-2}^{2}$. Note that the dimension $\mathrm{p}-1$ is the number of rows of $\mathrm{C}$. 


\section{Empirical Findings}

To select the most important variables from the crime data we employed the principal component analysis to classify the data into major components, and then in the second stage we select the most important variable from each component. Results of the eigen values and corresponding eigen vectors of correlation matrix in table (3) indicate the cumulative percentage of eigen values suggest the largest four eigen values explain about $98.9 \%$ of total variability of the crime data. As a result, our selection process of the number of components conclude four major components form the data set. Given variables selection process is based on the largest (absolute value) coefficient values from each component (eigen vector) the variables of illegal drugs, theft, murder, and forger are the variables to be included in the analysis. The canonical correlation analysis attempt to assess the degree of association between the major four crimes, illegal drugs, murder, theft, and adultery, with institutional weakness indicators which include increase in other four crimes: duty \& customs, forger, passport, and firearms \& ammunition crimes. These four crimes has been taken as indicators of institutional weakness because any surge in these crimes is a reflection of corruption or negligence, or incompetence (or the three together) in institutional performance. The canonical correlation results indicate there is a very high association between the two set of the data, which is about 0.78 and highly significant according to Wilks' test result.This finding imply institutional weakness can nurture crime surge in the country. Profile analysis reveal there is a significant increase in crime rate between the years 2014-2015, as indicated by the $T^{2}$ statistic test result. Cluster analysis in table (4), indicate the type of crimes in Darfor region are featured in the rest of the country except in the capital state, Khartoum which represent a separate cluster on its own. Cluster analysis summary in figure (1) indicate murder crime is connected with adultery; and theft crime is associated with fire arms \& ammunition crimes. Custom \& duty crimes connected with passport and illegal drugs crimes. However, illegal drugs crime is associated with a number of crimes including murder, theft, and adultery.

\begin{tabular}{l|l|l|l|l|l}
\multicolumn{7}{c}{ Table-3. Principal components } \\
\hline $\begin{array}{l}\text { Eigen } \\
\text { values }\end{array}$ & $\mathbf{7 . 0 6}$ & $\mathbf{1 . 1 4}$ & $\mathbf{0 . 6 3}$ & $\mathbf{0 . 0 6 7}$ & $\mathbf{0 . 0 5 5}$ \\
\hline $\begin{array}{l}\text { Cumulative } \\
\begin{array}{c}\text { of eigen } \\
\text { values }\end{array}\end{array}$ & 0.78 & 0.91 & 0.98 & 0.98 & 0.99 \\
\hline \multirow{2}{*}{$\begin{array}{l}\text { Eigen } \\
\text { vectors }\end{array}$} & $\mathrm{v} 1$ & $\mathrm{v} 2$ & $\mathrm{v} 3$ & $\mathrm{v} 4$ & $\mathrm{v} 5$ \\
\cline { 2 - 6 } & -0.35 & -0.07 & 0.15 & 0.83 & -0.11 \\
\cline { 2 - 6 } & -0.37 & -0.02 & -0.01 & -0.11 & 0.18 \\
\cline { 2 - 6 } & -0.19 & 0.52 & -0.81 & 0.06 & -0.07 \\
\cline { 2 - 6 } & -0.37 & -0.04 & -0.01 & -0.06 & -0.05 \\
\cline { 2 - 6 } & -0.05 & -0.83 & -0.54 & 0.03 & -0.02 \\
\cline { 2 - 6 } & -0.37 & -0.01 & 0.01 & -0.06 & 0.33 \\
\cline { 2 - 6 } & -0.36 & -0.08 & 0.09 & -0.50 & -0.01 \\
\cline { 2 - 6 } & -0.37 & -0.07 & 0.01 & 0.04 & 0.46 \\
\cline { 2 - 6 } & -0.36 & -0.06 & 0.08 & -0.14 & -0.78 \\
\hline
\end{tabular}

Table-4. Cluster Groups

\begin{tabular}{l|l}
\hline Clusters & Groups \\
\hline C1 & East Darfor, West Darfor \\
\hline C2 & Blue Nile, East Darfor, West Darfor \\
\hline C3 & Kassala, North Darfor \\
\hline C4 & River Nile, Kassala, North Darfor \\
\hline C5 & Red Sea, Gadarif \\
\hline C6 & South Kordofan, Blue Nile, Eas Darfor, West Darfor \\
\hline C7 & North Kordofan, Red Sea Gadarif \\
\hline C8 & West Kordofan, North Kordofan, Red Sea, Gadarif \\
\hline C9 & Northern, South Kordofan, Blue Nile, East Darfor, West Darfor \\
\hline C10 & River Nile, Kassala, Red Sea, Northern, South Kordofan, Blue Nile, East Darfor, West Darfor \\
\hline C11 & Senar, River Nile, Kassala, Red Sea, Northern, South Kordofan, Blue Nile, East Darfor, West Darfor \\
\hline C12 & White Nile, West Kordofan, North Kordofan, Red Sea, Gadarif \\
\hline C13 & Gazira, South Darfor \\
\hline C14 & White Nile, West Kordofan, North Kordofan, Red Sea, Gadarif, C11 \\
\hline C15 & Central Darfor, C14 \\
\hline C16 & Khartoum \\
\hline
\end{tabular}

\subsection{Profile Analysis}

T-Square test for the null hypothesis of equal means: $\mathrm{T} 2$

$\begin{array}{llll}-61.03939 & 1059.545 & -14.63202 & -7.915809\end{array}$


Plot-1. Profile analysis: two sample means

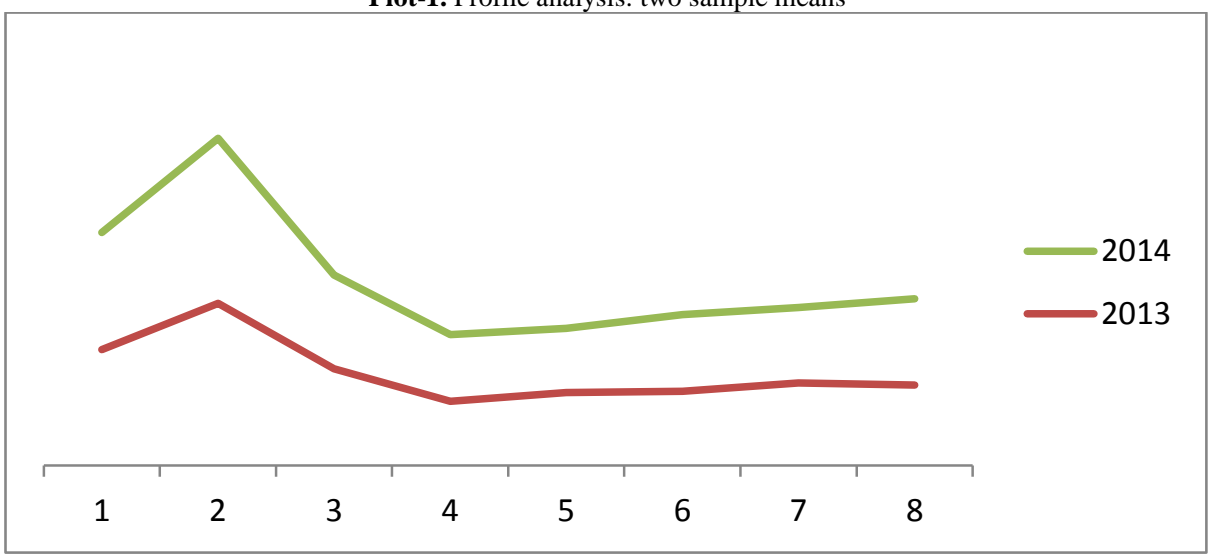

Figure-1. Dendrogram applied to cluster analysis findings

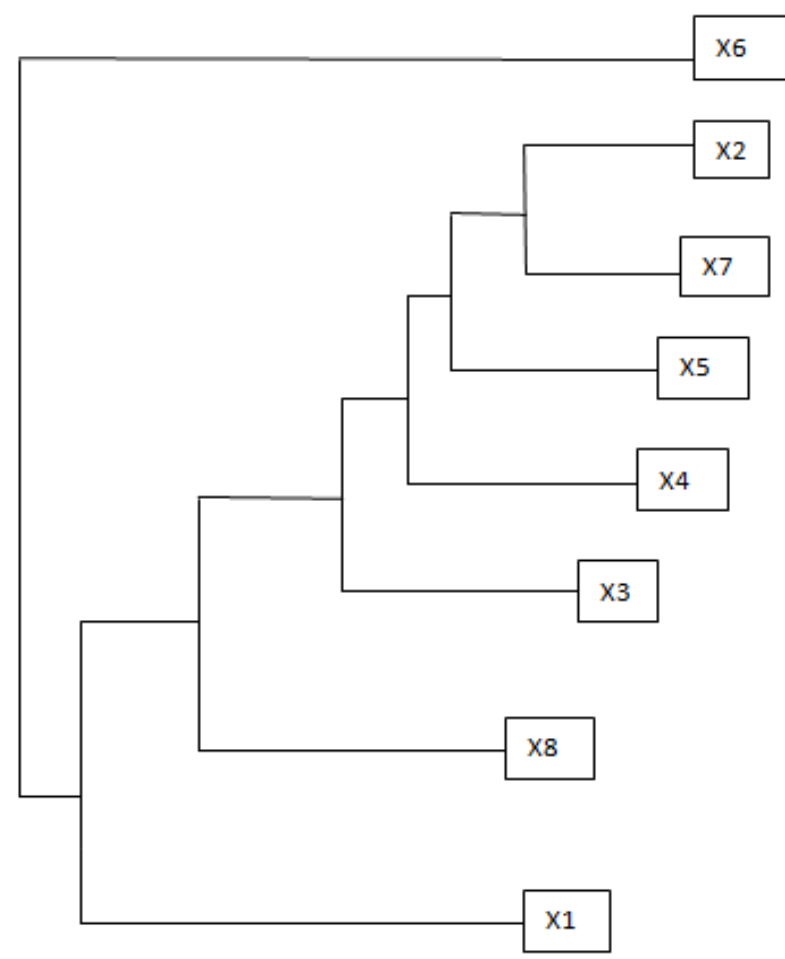

Core crimes:

$\mathrm{X} 1=$ illegal drugs

$\mathrm{X} 2=$ theft and robbery

$\mathrm{X} 3=$ murder

$\mathrm{X} 4=$ adultery

Institutional weakness indicators:

$\mathrm{X} 5=$ forger crimes

$\mathrm{X} 6=$ duty and custom crimes

$\mathrm{X} 7=$ fire arms and ammunition crimes

$\mathrm{X} 8=$ passport crimes

\section{Concluding Remarks}

To capture the pattern and trend of crime in the country the current research uses a number of multivariate statistical methods, including cluster analysis, principal component analysis, profile analysis, and canonical correlation analysis. The data employed in the research include crime data for all 18 states in the country during the years 2014 - 2013. The variables under investigation include four major crimes, and other four crimes intended to reflect institutional weakness. The first group include the crimes of murder, illegal drugs, adultery, and theft, while the second group include passport, tariffs \& custom, weapons \& ammunition, and medical drugs \& pharmaceutical 
crimes. Our findings indicate profile analysis reveal the upswing in the major crime rates during $2014-2015$ is statistically significant, and the canonical correlation analysis show there is strong significant association between the major four crimes and the institutional weakness indicators. Cluster analysis indicate the type of crimes in Darfor region are featured in the rest of the country except in the capital state, Khartoum which represent a separate cluster. Cluster analysis also indicate murder crime is connected with adultery; and theft crime is associated with firearms \& ammunition crimes. Custom \& duty crimes connected with passport and illegal drugs crimes. However, illegal drugs crime is associated with a number of crimes including murder, theft, and adultery.

\section{References}

Rencher, A. (2002). Methods of multivariate analysis. 2 edn: Wiley Interscience publisher.

Rotberg, R. (2002). The New nature of nation-state failure. Washington Quarterly, 25: 85-96.

\section{Appendix A}

Principal components:

EIGENVALUES

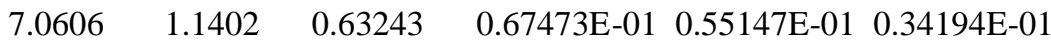

$0.50164 \mathrm{E}-02 \quad 0.34215 \mathrm{E}-02 \quad 0.15001 \mathrm{E}-02$

SUM OF EIGENVALUES = 9.0000

CUMULATIVE PERCENTAGE OF EIGENVALUES

$\begin{array}{llllll}0.78452 & 0.91120 & 0.98147 & 0.98897 & 0.99510 & 0.99890\end{array}$

$0.99945 \quad 0.99983 \quad 1.0000$

\section{EIGENVECTORS}

\begin{tabular}{|c|c|c|c|c|c|}
\hline \multicolumn{6}{|l|}{ VECTOR 1} \\
\hline-0.36221 & -0.37514 & -0.19291 & -0.37496 & 0.05284 & -0.37403 \\
\hline-0.36670 & -0.37203 & -0.36701 & & & \\
\hline \multicolumn{6}{|c|}{ VECTOR 2} \\
\hline-0.07363 & -0.02513 & 0.52903 & -0.04776 & -0.83283 & -0.01983 \\
\hline-0.08752 & -0.07547 & -0.06665 & & & \\
\hline \multicolumn{6}{|c|}{ VECTOR 3} \\
\hline 0.15639 & -0.00623 & -0.81222 & 0.00523 & -0.54712 & 0.01433 \\
\hline 0.09795 & 0.00088 & 0.08148 & & & \\
\hline \multicolumn{6}{|c|}{ VECTOR 4} \\
\hline 0.83537 & -0.11266 & 0.06161 & -0.06787 & 0.03478 & -0.06008 \\
\hline-0.50377 & 0.04089 & -0.14419 & & & \\
\hline \multicolumn{6}{|c|}{ VECTOR 5} \\
\hline-0.11033 & 0.18243 & -0.07739 & -0.05440 & -0.02795 & 0.33372 \\
\hline-0.00466 & 0.46092 & -0.78802 & & & \\
\hline \multicolumn{6}{|c|}{ VECTOR 6} \\
\hline-0.35253 & -0.01334 & -0.09895 & 0.22463 & -0.02531 & 0.30156 \\
\hline-0.73470 & 0.27134 & 0.33214 & & & \\
\hline \multicolumn{6}{|c|}{ VECTOR 7} \\
\hline-0.04059 & 0.62864 & -0.01081 & -0.57098 & -0.00958 & -0.37476 \\
\hline-0.12257 & 0.28493 & 0.20071 & & & \\
\hline \multicolumn{6}{|c|}{ VECTOR 8} \\
\hline-0.04154 & -0.39617 & 0.02674 & 0.25915 & -0.03816 & -0.59416 \\
\hline 0.10347 & 0.63874 & 0.01631 & & & \\
\hline \multicolumn{6}{|c|}{ VECTOR 9} \\
\hline-0.03560 & 0.51020 & -0.05293 & 0.63710 & -0.00967 & -0.40014 \\
\hline-0.17015 & -0.28103 & -0.24817 & & & \\
\hline
\end{tabular}


FACTOR MATRIX (9 FACTORS)

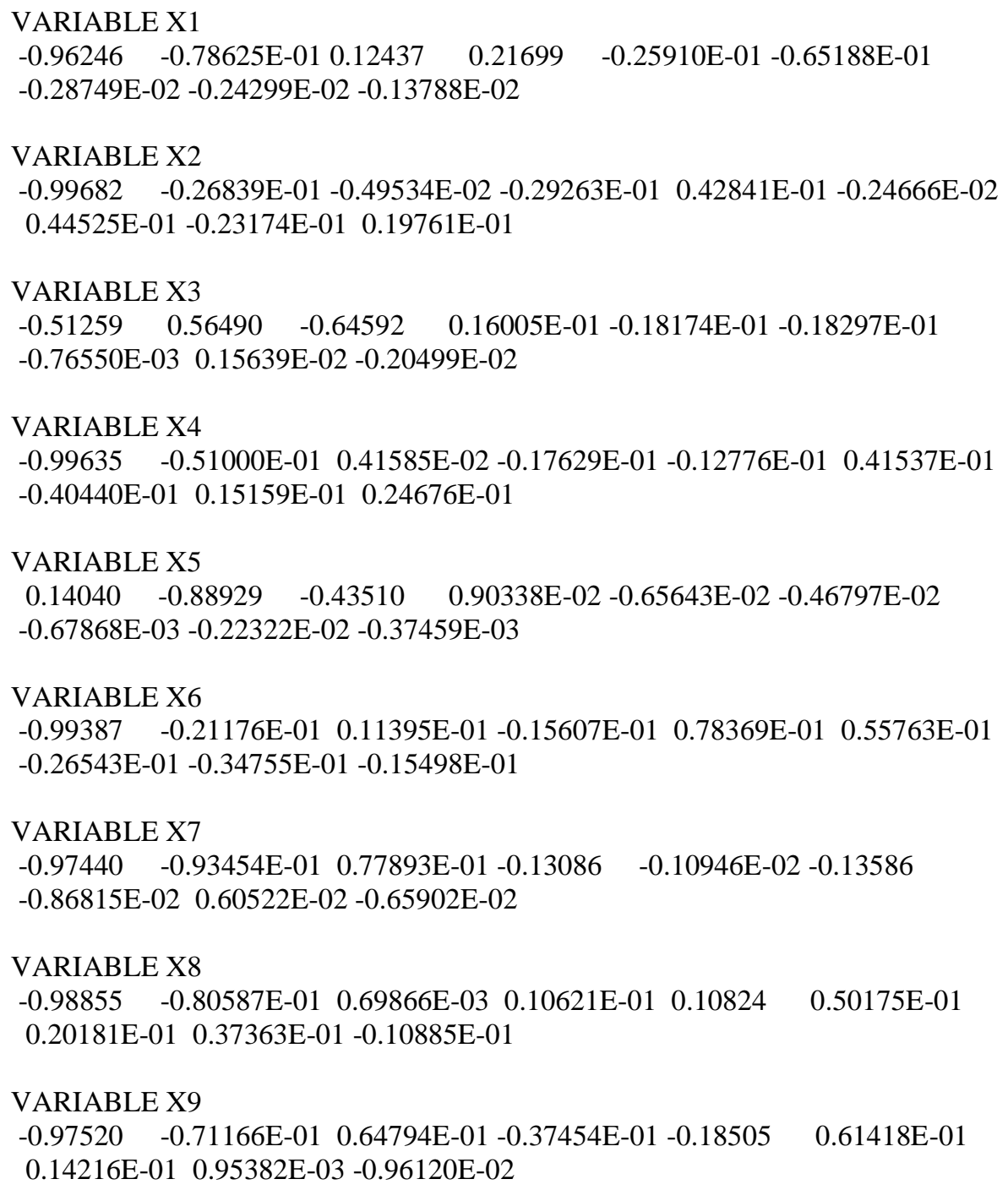

\section{VARIABLE X2}

-0.99682 -0.26839E-01 -0.49534E-02 -0.29263E-01 0.42841E-01 -0.24666E-02 $0.44525 \mathrm{E}-01-0.23174 \mathrm{E}-01 \quad 0.19761 \mathrm{E}-01$

\section{VARIABLE X4}

-0.99635 -0.51000E-01 0.41585E-02 -0.17629E-01 -0.12776E-01 0.41537E-01

$-0.40440 \mathrm{E}-01 \quad 0.15159 \mathrm{E}-01 \quad 0.24676 \mathrm{E}-01$

\section{VARIABLE X6}

-0.99387 -0.21176E-01 0.11395E-01 -0.15607E-01 0.78369E-01 0.55763E-01

$-0.26543 \mathrm{E}-01-0.34755 \mathrm{E}-01-0.15498 \mathrm{E}-01$

\section{VARIABLE X8}

$\begin{array}{llllll}-0.98855 & -0.80587 E-01 & 0.69866 \mathrm{E}-03 & 0.10621 \mathrm{E}-01 & 0.10824 & 0.50175 \mathrm{E}-01\end{array}$ $0.20181 \mathrm{E}-01 \quad 0.37363 \mathrm{E}-01-0.10885 \mathrm{E}-01$

\section{VARIABLE X9}

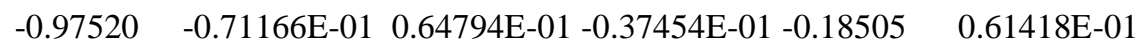
$0.14216 \mathrm{E}-01 \quad 0.95382 \mathrm{E}-03-0.96120 \mathrm{E}-02$

\section{Appendix B:}

Correlation matrix \& Canonical Correlation

\begin{tabular}{l|l|l|l|l|l|l|l|l|l}
\hline & & $\mathbf{x 1}$ & $\mathbf{x 2}$ & $\mathbf{x 3}$ & $\mathbf{x 4}$ & $\mathbf{x 5}$ & $\mathbf{x 6}$ & $\mathbf{x 7}$ & $\mathbf{x 8}$ \\
\hline Drugs & $\mathrm{x} 1$ & 1 & 0.95 & 0.37 & 0.94 & 0.95 & -0.11 & 0.95 & -0.95 \\
\hline theft & $\mathrm{x} 2$ & 0.95 & 1 & 0.49 & 0.96 & 0.99 & -0.11 & 0.99 & 0.99 \\
\hline Murder & $\mathrm{x} 3$ & 0.37 & 0.49 & 1 & 0.42 & 0.47 & -0.29 & 0.48 & 0.45 \\
\hline adultery & $\mathrm{x} 4$ & 0.94 & 0.96 & 0.42 & 1 & 0.98 & -0.1 & 0.96 & 0.95 \\
\hline forger & $\mathrm{x} 5$ & 0.95 & 0.99 & 0.47 & 0.98 & 1 & -0.09 & 0.99 & 0.98 \\
\hline duty, customs & $\mathrm{x} 6$ & -0.11 & -0.11 & -0.29 & -0.1 & -0.09 & 1 & -0.12 & -0.68 \\
\hline fire arms & $\mathrm{x} 7$ & 0.95 & 0.99 & 0.48 & 0.96 & 0.99 & -0.12 & 1 & 0.99 \\
\hline passport & $\mathrm{x} 8$ & -0.95 & 0.99 & 0.45 & 0.95 & 0.98 & -0.68 & 0.99 & 1 \\
\hline
\end{tabular}

Canonical correlation (C), Wilk stat (W), eigen values (R1) of the correlation matrix:

$\mathrm{C}$

0.7798594

W

$0.2983558 \mathrm{E}-01$

$\mathrm{CHI}$

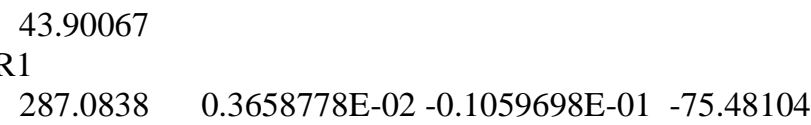


Appendix C:

Crime clusters

\begin{tabular}{|c|c|c|c|c|c|c|c|c|c|}
\hline Correlation Matrix & & $\mathbf{x 1}$ & $\mathbf{x} 2$ & $\mathbf{x} 3$ & $x 4$ & $\mathbf{x 5}$ & $\mathbf{x 6}$ & $\mathbf{x} 7$ & $\mathbf{x 8}$ \\
\hline drugs & $\mathrm{x} 1$ & 1 & 0.95 & 0.37 & 0.94 & 0.95 & -0.11 & 0.95 & -0.95 \\
\hline theft & $\mathrm{x} 2$ & 0.95 & 1 & 0.49 & 0.96 & 0.99 & -0.11 & 0.99 & 0.99 \\
\hline murder & $\mathrm{x} 3$ & 0.37 & 0.49 & 1 & 0.42 & 0.47 & -0.29 & 0.48 & 0.45 \\
\hline adultery & $\mathrm{x} 4$ & 0.94 & 0.96 & 0.42 & 1 & 0.98 & -0.1 & 0.96 & 0.95 \\
\hline forger & $\mathrm{x} 5$ & 0.95 & 0.99 & 0.47 & 0.98 & 1 & -0.09 & 0.99 & 0.98 \\
\hline duty, customs & $\mathrm{x} 6$ & -0.11 & -0.11 & -0.29 & -0.1 & -0.09 & 1 & -0.12 & -0.68 \\
\hline firearms & $\mathrm{x} 7$ & 0.95 & 0.99 & 0.48 & 0.96 & 0.99 & -0.12 & 1 & 0.99 \\
\hline \multirow[t]{10}{*}{ passport } & $\mathrm{x} 8$ & -0.95 & 0.99 & 0.45 & 0.95 & 0.98 & -0.68 & 0.99 & 1 \\
\hline & & $\mathrm{x} 1$ & $\mathrm{x} 2$ & $\mathrm{x} 3$ & $\mathrm{x} 4$ & $\mathrm{x} 5$ & x6 & $\mathrm{x} 7$ & $\mathrm{x} 8$ \\
\hline & $\mathrm{x} 1$ & 0.00 & 1.95 & 1.93 & 1.90 & 1.94 & 2.72 & 1.95 & 2.82 \\
\hline & $\mathrm{x} 2$ & 1.95 & 0.00 & 1.42 & 0.10 & 0.04 & 3.24 & 0.02 & 1.98 \\
\hline & $\mathrm{x} 3$ & 1.93 & 1.42 & 0.00 & 1.41 & 1.43 & 2.48 & 2.48 & 1.88 \\
\hline & $\mathrm{x} 4$ & 1.90 & 0.10 & 1.41 & 0.00 & 0.08 & 3.18 & 0.10 & 1.98 \\
\hline & $\mathrm{x} 5$ & 1.94 & 0.04 & 1.43 & 0.08 & 0.00 & 3.23 & 0.04 & 1.99 \\
\hline & $x 6$ & 2.72 & 3.24 & 2.48 & 3.18 & 3.23 & 0.00 & 3.24 & 3.40 \\
\hline & $\mathrm{x} 7$ & 1.95 & 0.02 & 2.48 & 0.10 & 0.04 & 3.24 & 0.00 & 1.98 \\
\hline & $\mathrm{x} 8$ & 2.82 & 1.98 & 1.88 & 1.98 & 1.99 & 3.40 & 1.98 & 0.00 \\
\hline \multicolumn{10}{|l|}{$\mathrm{C} 1=\mathrm{x} 2, \mathrm{x} 7$} \\
\hline & & $\mathrm{x} 1$ & $\mathrm{C} 1$ & $\mathrm{x} 3$ & $\mathrm{x} 4$ & $\mathrm{x} 5$ & $\mathrm{x} 6$ & $\mathrm{x} 8$ & \\
\hline & $\mathrm{x} 1$ & 0.00 & 1.95 & 1.93 & 1.90 & 1.94 & 2.72 & 2.82 & \\
\hline & $\mathrm{C} 1$ & 1.95 & 0.00 & 1.42 & 0.10 & 0.04 & 3.24 & 1.98 & \\
\hline & $\mathrm{x} 3$ & 1.93 & 1.42 & 0.00 & 1.41 & 1.43 & 2.48 & 1.88 & \\
\hline & $\mathrm{x} 4$ & 1.90 & 0.10 & 1.41 & 0.00 & 0.08 & 3.18 & 1.98 & \\
\hline & $\mathrm{x} 5$ & 1.94 & 0.04 & 1.43 & 0.08 & 0.00 & 3.23 & 1.99 & \\
\hline & $x 6$ & 2.72 & 3.24 & 2.48 & 3.18 & 3.23 & 0.00 & 3.40 & \\
\hline & $\mathrm{x} 8$ & 2.82 & 1.98 & 1.88 & 1.98 & 1.99 & 3.40 & 0.00 & \\
\hline \multicolumn{10}{|l|}{$\mathrm{C} 2=\mathrm{C} 1, \mathrm{x} 5$} \\
\hline & & $\mathrm{x} 1$ & $\mathrm{x} 3$ & $\mathrm{x} 4$ & $\mathrm{C} 2$ & $x 6$ & $\mathrm{x} 8$ & & \\
\hline & $\mathrm{x} 1$ & 0.00 & 1.93 & 1.90 & 1.94 & 2.72 & 2.82 & & \\
\hline & $\mathrm{x} 3$ & 1.93 & 0.00 & 1.41 & 1.42 & 2.48 & 1.88 & & \\
\hline & $\mathrm{x} 4$ & 1.90 & 1.41 & 0.00 & 0.08 & 3.18 & 1.98 & & \\
\hline & $\mathrm{C} 2$ & 1.94 & 1.42 & 0.08 & 0.00 & 3.23 & 1.98 & & \\
\hline & $\mathrm{x} 6$ & 2.72 & 2.48 & 3.18 & 3.23 & 0.00 & 3.40 & & \\
\hline & $\mathrm{x} 8$ & 2.82 & 1.88 & 1.98 & 1.98 & 3.40 & 0.00 & & \\
\hline \multicolumn{10}{|l|}{$\mathrm{C} 3=\mathrm{C} 2, \mathrm{x} 4$} \\
\hline & & $\mathrm{x} 1$ & $\mathrm{x} 3$ & $\mathrm{C} 3$ & $x 6$ & $\mathrm{x} 8$ & & & \\
\hline & $\mathrm{x} 1$ & 0.00 & 1.93 & 1.90 & 2.72 & 2.82 & & & \\
\hline & $\mathrm{x} 3$ & 1.93 & 0.00 & 1.41 & 2.48 & 1.88 & & & \\
\hline & $\mathrm{C} 3$ & 1.90 & 1.41 & 0.00 & 3.18 & 1.98 & & & \\
\hline & $\mathrm{x} 6$ & 2.72 & 2.48 & 3.18 & 0.00 & 3.40 & & & \\
\hline & $\mathrm{x} 8$ & 2.82 & 1.88 & 1.98 & 3.40 & 0.00 & & & \\
\hline \multicolumn{10}{|l|}{$\mathrm{C} 4=\mathrm{x} 3, \mathrm{C} 3$} \\
\hline & & $\mathrm{x} 1$ & $\mathrm{C} 4$ & $\mathrm{x} 6$ & $\mathrm{x} 8$ & & & & \\
\hline & $\mathrm{x} 1$ & 0.00 & 1.90 & 2.72 & 2.82 & & & & \\
\hline & $\mathrm{C} 4$ & 1.90 & 0.00 & 2.48 & 1.88 & & & & \\
\hline & $\mathrm{x} 6$ & 2.72 & 2.48 & 0.00 & 3.40 & & & & \\
\hline & $\mathrm{x} 8$ & 2.82 & 1.88 & 3.40 & 0.00 & & & & \\
\hline \multicolumn{10}{|l|}{$\mathrm{C} 5=\mathrm{x} 8, \mathrm{C} 4$} \\
\hline & & $\mathrm{x} 1$ & C5 & $\mathrm{x} 6$ & & & & & \\
\hline & $\mathrm{x} 1$ & 0.00 & 1.90 & 2.72 & & & & & \\
\hline & $\mathrm{C} 5$ & 1.90 & 0.00 & 2.48 & & & & & \\
\hline & $\mathrm{x} 6$ & 2.72 & 2.48 & 0.00 & & & & & \\
\hline \multicolumn{10}{|l|}{$\mathrm{C} 6=\mathrm{x} 1, \mathrm{C} 5$} \\
\hline & & $\mathrm{x} 1$ & & $\mathrm{x} 6$ & & & & & \\
\hline & C6 & 0.00 & & 2.48 & & & & & \\
\hline & $\mathrm{x} 6$ & 2.48 & & 0.00 & & & & & \\
\hline \multicolumn{10}{|l|}{$\mathrm{C} 7=\mathrm{x} 6, \mathrm{C} 6$} \\
\hline $\mathrm{c} 7=\mathrm{x} 1, \mathrm{x} 6$ & & & & & & & & & \\
\hline
\end{tabular}

